\title{
Drinking patterns and hydration biomarkers among young adults with different levels of habitual total drinking fluids intake in Baoding, Hebei Province, China: a cross- sectional study
}

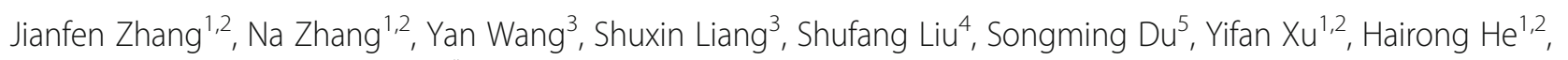
Hao Cai ${ }^{1,2}$ and Guansheng $\mathrm{Ma}^{1,2^{*}}$

\begin{abstract}
Background: The purposes were to investigate the drinking patterns and hydration biomarkers among young adults with different levels of habitual total drinking fluids intake.

Methods: A cross-sectional study was conducted among 159 young adults aged 18-23 years in Baoding, China. Total drinking fluids and water from food were assessed by 7-day 24-h fluid intake questionnaire and duplicate portion method, respectively. The osmolality and electrolyte concentrations of the $24 \mathrm{~h}$ urine and fasting blood samples were tested. Differences in $\mathrm{LD}_{1}$ (low drinker), $\mathrm{LD}_{2}, \mathrm{LD}_{3}$ and $\mathrm{HD}$ (high drinker) groups, stratified according to the quartiles of total drinking fluids, were compared using one-way ANOVA, Kruskal-Wallis $\mathrm{H}$ test and chi-square test.

Results: A total of 156 participants (80 males and 76 females) completed the study. HD group had greater amounts of TWI (Total Water Intake), water from food, higher and lower contributions of total drinking fluids and water from food to TWI, respectively, than $L D_{1}, L D_{2}$ and $L D_{3}$ groups $(p<0.05)$. Participants in $H D$ group had higher amounts of water and water from dishes than participants in $L D_{1}, L D_{2}$ and $L D_{3}$ groups $(p<0.05)$. No significant differences were found in the contributions of different fluids to total drinking fluids within the four groups $(p>0.05)$. The osmolality of urine was $59-143 \mathrm{mOsm} / \mathrm{kg}$ higher in $\mathrm{LD}_{1}$ than that in $\mathrm{LD}_{2}, \mathrm{LD}_{3}$ and $\mathrm{HD}$ group $(p<0.05)$. The percentage of participants in optimal hydration status increased from $12.8 \%$ in $\mathrm{LD}_{1}$ group to $56.4 \%$ in $\mathrm{HD}$ group $(p<0.05)$. HD and $L_{3}$ groups had 386 793 higher volumes of urine than that of $L_{1}$ and $L_{2}$ groups $(p<0.05)$. Differences were found in the concentrations of electrolytes among the four groups $(p<0.05)$. No significant differences were found in the plasma biomarkers $(p>0.05)$, with the exception of higher concentration of $\mathrm{Mg}$ in $\mathrm{LD}_{3}$ and $\mathrm{HD}$ groups than (Continued on next page)
\end{abstract}

\footnotetext{
* Correspondence: mags@bjmu.edu.cn

'Department of Nutrition and Food Hygiene, School of Public Health, Peking University, 38 Xue Yuan Road, Haidian District, Beijing 100191, China

²aboratory of Toxicological Research and Risk Assessment for Food Safety, Peking University, 38 Xue Yuan Road, Haidian District, Beijing 100191, China Full list of author information is available at the end of the article
}

(c) The Author(s). 2020 Open Access This article is licensed under a Creative Commons Attribution 4.0 International License, which permits use, sharing, adaptation, distribution and reproduction in any medium or format, as long as you give appropriate credit to the original author(s) and the source, provide a link to the Creative Commons licence, and indicate if changes were made. The images or other third party material in this article are included in the article's Creative Commons licence, unless indicated otherwise in a credit line to the material. If material is not included in the article's Creative Commons licence and your intended use is not permitted by statutory regulation or exceeds the permitted use, you will need to obtain permission directly from the copyright holder. To view a copy of this licence, visit http://creativecommons.org/licenses/by/4.0/ The Creative Commons Public Domain Dedication waiver (http://creativecommons.org/publicdomain/zero/1.0/) applies to the data made available in this article, unless otherwise stated in a credit line to the data. 
(Continued from previous page)
that in $L D_{1}$ and $L D_{2}$ groups $(p<0.05)$.

Conclusions: Participants with higher total drinking fluids had better drinking pattern and hydration status. Interventions should be undertaken to advise adults to have adequate total drinking fluids, in order to keep in optimal hydration status.

Trial registration: The registration number was ChiCTR-ROC-17010320, which was registered on the Chinese clinical trial registry.

Keywords: Hydration biomarkers, Drinking patterns, Total drinking fluids

\section{Background}

Water is of vital importance for the health of humans. Water accounts for almost $50-60 \%$ of the total body mass of adults [1]. Moreover, water plays important role in facilitating cellular metabolism, modulating normal osmotic pressure and regulating the temperature of the body [2]. In addition, water intake has also been associated with mood state in women [3]. Insufficient water intake may lead body into dehydration. Researches have shown that dehydration can impair the physical $[4,5]$ and cognitive performances $[6,7]$, which included vigilance attention [8], working memory $[9,10]$ and executive function [11]. Moreover, dehydration may also have deleterious effects om cardiovascular health [12]. Therefore, it is important for people to be in optimal hydration status.

To keep the body functioning properly, people need to consume adequate volumes of water. Many factors such as individuals' (age, gender, etc.) and environmental conditions (temperature, humidity, etc.) influence the requirements of fluids. Consequently, the dietary reference values of adequate intake of TWI (total water intake, including total drinking fluids and water from food), such as the EFSA (European Food Safety Authority) [13], the United States [14] and China [15] were different. Yet only $40 \%$ of men and $60 \%$ of women in 13 countries drank more than the adequate intake of water from fluids set by EFSA [16]. Among children from 19 countries, $60 \pm 24 \%$ of them failed to have adequate water with guidelines, suggesting that children were not consuming enough water to be adequately hydrated [17]. Moreover, in China, about $32 \%$ of adults, children and adolescents drank less fluids than the recommendation [18], which potentially may have adverse effects on their health. Unfortunately, the hydration biomarkers were not measured in the studies mentioned above. Studies reporting the hydration status among people in freeliving conditions were scarce. Data of 2009 to 2012 National Health and Nutrition Examination Survey demonstrated that $29.5 \%$ of US adults aged $20-74$ years were not in optimal hydration status [19]. While among elderly aged $\geq 60$ years from NHANES 2011-2014, 29.6\% and $33.3 \%$ of women and men had Sosm (osmolality of serum) levels indicative of impending dehydration, with $10.2 \%$ and $12.6 \%$ of women and men had Sosm levels indicative of dehydration [20]. In China, there was merely one study exploring hydration status among male young adults, which showed that only $35.3 \%$ of them were in optimal hydration status [21]. Research showed that the participants with low total drinking fluids excreted significantly less volume of urine than those with high total drinking fluids over each $24 \mathrm{~h}$ period [22]. In addition, the osmolality, specific gravity of urine among adults with high total drinking fluids were lower than those with low total drinking fluids [22]. Nevertheless, the differences in hydration biomarkers among participants with different levels of habitual total drinking fluids intake were not explored yet in China. More studies should include hydration biomarkers to investigate the hydration status of Chinese adults in the future.

Drinking patterns, defined here as the amounts and types of fluids consumed, have been associated with health [23, 24]. Water, which could reduce the total energy intake, may contribute to the regulation of body weight and help individuals reach the recommendation of TWI [25-28]. Moreover, the replacement of diet beverages with water may improve the insulin resistance of people [28]. A rising number of studies asserted that there were positive associations between SSBs (sugar-sweetened beverages) and the risk of weight gain or obesity or metabolic syndrome or obesity-related cancers and type 2 diabetes in adults, children and adolescents [29-34]. Moreover, the consumption of SSBs was also associated with short sleep in middle school students [35]. Therefore, the sources of total drinking fluids were worth exploring. However, the drinking patterns may differ among people from different countries, for instance, the Chinese tend to have tea, while the Americans prefer to drink more coffee [36]. The drinking patterns were not only different from countries, differences also existed among people from the same country. In France, the volumes of fluids such as water, were higher among adults with higher total drinking fluids intake than those with lower total drinking fluids intake [22]. However, in China, there was no study investigated the drinking patterns among participants with different levels of habitual total drinking fluids. 
In reference to the volumes of water from food, the contributions of water from food to TWI were different among countries, such as in the United States [37], in European countries [38] and in Japan [39]. Among adults in China, nearly $44 \%$ of the TWI came from food [40], however, the sources of water from food among young adults have not been reported. In addition, in France, the amount of water from food were $0.55 \mathrm{~L}$ and $0.68 \mathrm{~L}$ among participants with lower total drinking fluids intake and higher total drinking fluids intake, respectively [22]. However, there was no study investigating the differences in the sources of water from food among young adults with different levels of total drinking fluids. Therefore, it remains to be determined if participants with a low habitual total drinking fluids have a different contribution of water from food and different sources of water from food comparing with those with a high habitual total drinking fluids intake in Chinese.

The objectives of this study were, firstly, to investigate the differences in drinking patterns among young adults; secondly, to explore the hydration biomarkers among young adults with different levels of habitual total drinking fluids intake in free-living conditions. This will lead to the provision of a science-based education of fluids intake for young adults.

\section{Methods}

\section{Participants}

The inclusion criteria were that participants including males and females were healthy and aged 18-23 years. The exclusion criteria were that participants with smoking, habitual alcohol consumptions ( $>20 \mathrm{~g} /$ day) or habitual high caffeine consumptions ( $>250 \mathrm{mg} /$ day) or had chronic diseases or other diseases (gastrointestinal tract disease, diabetes, oral disease, kidney disease, cardiovascular disease or other chronic or metabolic diseases) were excluded from the study [41].

\section{Sample size calculation}

From a study performed among young male adults in China, the standard deviation of total drinking fluids was $468 \mathrm{~mL}$ [21]. Then, the SAS procedure (SAS Institute Inc., Cary, NC) was used to calculate the sample size. The $\delta$ set at $76 \mathrm{~mL}, \alpha$ set at 0.05 , and $10 \%$ drop-out rate was taken into account, 159 participants were needed in this study.

\section{Study procedure}

This was a cross-sectional study, which lasted for 7 consecutive days. On day 1, all participants were asked to take the anthropometric measurements including height, weight and waist circumference. After that, all participants were instructed to complete the self-designed 7day 24-h fluid intake questionnaire to record the fluids intake from water and other beverages from day 1 to day 7. To ensure the competence and accurateness of the fluids intake, the questionnaires were checked by investigators every day. All the food the participants ate for three consecutive days (two weekdays and one weekend day, from day 5 to day 7) during the 7 consecutive days were weighed and recorded. From day 5 to day 7, 24-h urine samples including the first morning urine of three consecutive days (two weekdays and one weekend day) were collected by participants. On day 6 , the fasting blood samples of all participants were collected. The temperature and humidity of indoor and outdoor was recorded each day for 7 days. The study procedure was shown in Fig. 1.

\section{Measurement of Total water intake}

Total water intake $(\mathrm{mL})=$ Total drinking fluids $(\mathrm{mL})+$ Water from food $(\mathrm{mL})$.

A self-designed 7-day 24-h fluid intake questionnaire was used to assess the total drinking fluids, as showed before. Moreover, the type and amount of drinking fluid for each time was measured using a cup to the nearest of $5 \mathrm{~mL}$. T According to the General standard for beverages of China (GB/T 1-789-2015) [42], all the drinking fluids were classified as below: water (plain water, tap water and bottle water), tea (fermented tea and semifermented tea), milk and milk products (liquid milk, yogurt and other milk products), SSBs (carbonated drinks, sports drinks, sweetened fruit juice, vegetable juice, protein drinks and other sugared drinks), alcohols(wine, beer, liquor, etc.) and other beverages [43].

In order to assess the amount of water from food, all foods the participants ate before and after were weighed for three consecutive days of the 7 days (including two weekdays and one weekend day, from day 5 to day 7). The duplicate portion method, with samples of food being collected and sent to the laboratory immediately, was used to measure the water from food. Samples of all foods were measured according to the national standard of GB 5009.3-2016 [44] and the water from fruits or other snacks was assessed according to the China Food Composition Table (2009) [45]. The water from food was classified as below: staple food (steamed bread, steamed rice, etc.), dishes (vegetables, meat, fish and eggs), porridge (millet porridge and other porridges), soup (tomato egg soup and other soups) and snacks (fruits, nuts, etc.) [43].

\section{Temperature and humidity of the environment}

The temperature and humidity of indoors and outdoors were recorded each day for 7 days (WSB-1-H2, Exasace, Zhengzhou, China). 


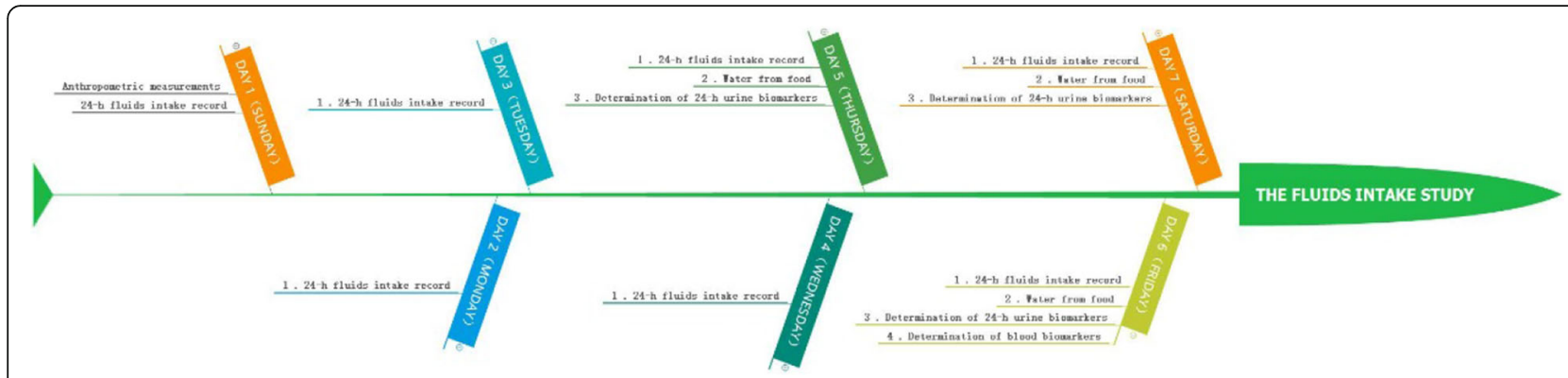

Fig. 1 The study procedure

\section{Anthropometric measurements}

Height, weight and waist circumference were measured twice with the participants wearing light clothes and barefoot [15] (HDM-300; Huaju, Zhejiang, China; Accu Measure, Greenwood Village, CO, USA). [BMI: weight (kg) / height squared (m)].

\section{Urine biomarkers}

The biomarkers of urine included the volumes, osmolality, $\mathrm{pH}$, urine specific gravity (USG) and the concentrations of electrolyte.

24-h urine samples including the first morning urine were collected by participants using self-designed containers. Every urine sample was collected and tested immediately. Before being measured, all urine samples were stored at $+4^{\circ} \mathrm{Cin}$ refrigerator. Urine volume was measured to the nearest $0.1 \mathrm{~g}$ using a desktop electronic scale (YP20001, SPC, Shanghai, China). Urine osmolality was assessed with freezing point method by osmotic pressure molar concentration meter (SMC 30C; Tianhe, Tianjin, China). USG, pH, urea and creatinine were tested by automatic urinary sediment analyzer with uric dry-chemistry method (H-800; Dirui, Changchun, China). Urine electrolyte concentrations (including sodium, potassium, chloride, calcium, magnesium and phosphate) were measured by automatic biochemical analyzer with the ion-selective electrode potentiometer method (AU 5800; Beckman, Brea, CA, USA). The optimal hydration was defined when urine osmolality $\leq 500$ $\mathrm{mOsm} / \mathrm{kg}$, middle hydration was defined as $500 \mathrm{mOsm} /$ $\mathrm{kg}<$ urine osmolality $\leq 800 \mathrm{mOsm} / \mathrm{kg}$, dehydration was defined as urine osmolality $>800 \mathrm{mOsm} / \mathrm{kg}[13,46]$.

\section{Plasma biomarkers}

Fasting blood samples were collected to measure the osmolality and electrolyte concentrations.

Plasma osmolality was assessed with freezing point method by osmotic pressure molar concentration meter (SMC 30C; Tianhe, Tianjin, China). The electrolyte concentrations (including sodium, potassium, chloride, calcium, magnesium and phosphate) were tested by automatic biochemical analyzer with the ion-selective electrode potentiometer method (AU 5800; Beckman, Brea, CA, USA).

\section{Statistics}

The SAS 9.2 software (SAS Institute Inc., Cary, NC, USA) was used for statistical analysis. The results were reported as mean \pm standard deviation (SD) if the data was normal distributed. While, median and quartile ranges ( $M$ and $Q$ ) was used to describe the data, which was not in normal distribution. Participants were divided into four groups, including $\mathrm{LD}_{1}$ (low drinker 1 ), $\mathrm{LD}_{2}$ (low drinker 2), $\mathrm{LD}_{3}$ (low drinker 3) and HD (high drinker) groups, according to the quartiles of total drinking fluids of participants (Q1: $324-858 \mathrm{~mL}, \mathrm{Q} 2: 859-$ $1135 \mathrm{~mL}, \mathrm{Q} 3:$ 1136-1478 mL, Q4: 1479-3033 mL). Oneway ANOVA, Kruskal-Wallis $\mathrm{H}$ test and chi-square test were used to compared the differences among the four groups. Differences between every two groups were compared using SNK (Student-Newman-Keuls) $(p<$ $0.05)$. Significance levels were set at $0.05(p<0.05)$.

\section{Results}

Eventually, a total of 159 participants were recruited, and 156 (80 males and 76 females) completed the study, with $98 \%$ complete rate. Table 1 showed the characteristics of the participants. Significant differences were found in the mean height and weight when comparing $\mathrm{LD}_{2}, \mathrm{LD}_{3}, \mathrm{HD}$ groups with group $\mathrm{LD}_{1}$, respectively $(p<$ $0.05)$, with no differences between $\mathrm{LD}_{2}, \mathrm{LD}_{3}$ and $\mathrm{HD}$ groups. There were no significant differences in age and BMI among the four groups $(p>0.05)$.

\section{Temperature and humidity}

The average indoor and outdoor temperature for the 7 days was $21.8^{\circ} \mathrm{C}$ and $20.7^{\circ} \mathrm{C}$, respectively. The average indoor and outdoor humidity was $39.9 \%$ and $35.9 \%$, respectively, see Table 2 .

\section{Measurement of total water intake}

TWI and water from food all increased with higher total drinking fluids among the four groups $(p<0.05)$. Participants in HD group had 515-1085 mL, 125-282 
Table 1 The characteristics of participants

\begin{tabular}{|c|c|c|c|c|c|c|}
\hline & $\mathrm{LD}_{1}(n=39)$ & $\mathrm{LD}_{2}(n=39)$ & $\mathrm{LD}_{3}(n=39)$ & $\mathrm{HD}(n=39)$ & Total $(n=156)$ & $P$ \\
\hline$\overline{\text { Age }(y)}$ & $19.6 \pm 1.1$ & $19.9 \pm 1.0$ & $19.8 \pm 1.1$ & $19.9 \pm 1.0$ & $19.8 \pm 1.1$ & 0.626 \\
\hline Height (cm) & $162.6 \pm 9.0^{\mathrm{a}}$ & $168.0 \pm 6.5$ & $166.7 \pm 8.6^{\mathrm{b}}$ & $167.6 \pm 8.1^{c}$ & $166.2 \pm 8.3$ & 0.014 \\
\hline Weight (kg) & $56.3 \pm 6.2^{a}$ & $63.5 \pm 11.3$ & $61.8 \pm 13.6^{b}$ & $63.8 \pm 12.5^{c}$ & $61.3 \pm 11.5$ & 0.013 \\
\hline BMI $\left(\mathrm{kg} / \mathrm{m}^{2}\right)$ & $21.3 \pm 2.0$ & $22.4 \pm 3.3$ & $22.1 \pm 4.1$ & $22.6 \pm 3.2$ & $22.1 \pm 3.3$ & 0.333 \\
\hline
\end{tabular}

Values are shown as the mean \pm standard deviation (SD). BMI: Body Mass Index

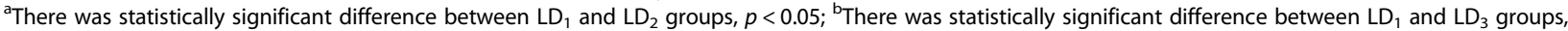
$p<0.05$; ${ }^{\mathrm{C}}$ There was statistically significant difference between $\mathrm{LD}_{1}$ and HD groups, $p<0.05$

$\mathrm{mL}$ and $664-1383 \mathrm{~mL}$ more than those in $\mathrm{LD}_{1}-\mathrm{LD}_{3}$ groups in total drinking fluids, water from food and TWI $(p<0.05)$, respectively. Contributions of total drinking fluids to TWI were different among the four groups comparing with each other $(p<0.05)$, ranging from $38.7 \%$ in $\mathrm{LD}_{1}$ group to $59.1 \%$ in the HD group. The water from food accounted for $61.3-40.9 \%$ of TWI from $\mathrm{LD}_{1}$ group to $\mathrm{HD}$ group, which were also significantly different among the four groups $(p<$ 0.05). Participants in HD group had a $20.4 \%$ higher and a $20.4 \%$ lower contribution of total drinking fluids and water from food to TWI than those in $\mathrm{LD}_{1}$ group, respectively $(p<0.05)$.

\section{Drinking patterns}

The main contributor of total drinking fluids was water in the four groups, which accounted for $77.3-85.6 \%$ and there were no significant differences among $\mathrm{LD}_{1}, \mathrm{LD}_{2}$, $\mathrm{LD}_{3}$ and HD groups $(p>0.05)$. Significant differences were found in the amounts of water in the four groups $(p<0.05)$, with the amounts of water increased with higher total drinking fluids. Nevertheless, there were no statistically significantly differences in the amounts of tea, milk and milk products, SSBs, alcoholic and other beverages among the four groups $(p>0.05)$. Moreover, there were no significant differences in the contributions of tea, milk and milk products, SSBs, alcoholic and other beverages to total drinking fluids among the four groups $(p>0.05)$. SSBs were the second contributor to total drinking fluids followed water in the $\mathrm{LD}_{1}, \mathrm{LD}_{2}, \mathrm{LD}_{3}$ groups, but in the HD group, milk and milk products followed water.

\section{Water from food}

Participants in HD group had 125-282 mL more water from food than those in other groups. The main contributor to water from food was dishes followed by staple food in all four groups. Participants in HD group had higher volumes of water from dishes and snacks than participants in $\mathrm{LD}_{1}, \mathrm{LD}_{2}$ and $\mathrm{LD}_{3}$ groups $(p<0.05)$. There were no statistically significant differences in the amounts of water from staple food, soup and porridge in the four groups $(p>0.05)$. Regarding the contributions of water from different foods, the contributions of water from snacks were different among the four groups $(p<$ 0.05), as shown in Table 3.

\section{Measurement of urine indexes}

Table 4 showed that the volumes of urine increased from $\mathrm{LD}_{1}$ group, to $\mathrm{HD}$ group, while the osmolality, USG, and the concentrations of $\mathrm{Na}, \mathrm{K}, \mathrm{Cl}, \mathrm{Ca}, \mathrm{Mg}$, phosphate, creatinine, uric acid and urea of urine were significantly different in $\mathrm{LD}_{1}, \mathrm{LD}_{2}, \mathrm{LD}_{3}$ and $\mathrm{HD}$ groups $(p<0.05)$. The percentages of participants in optimal hydration status was statistical higher in $\mathrm{HD}$ and $\mathrm{LD}_{3}$ groups than that in $\mathrm{LD}_{1}, \mathrm{LD}_{2}$ groups $(p<0.05)$.

Table 2 The temperature and humidity of study days

\begin{tabular}{lllll}
\hline & \multicolumn{2}{l}{ Indoors } & Outdoors & \\
\cline { 2 - 4 } & Temperature $\left({ }^{\circ} \mathrm{C}\right)$ & Humidity $(\%)$ & 18.1 & Humidity $(\%)$ \\
\hline Sunday & 19.9 & 43 & 22.4 & 37 \\
Monday & 23.0 & 48 & 24.0 & 41 \\
Tuesday & 23.3 & 31 & 17.9 & 29 \\
Wednesday & 21.5 & 48 & 21.0 & 32 \\
Thursday & 21.5 & 40 & 19.2 & 36 \\
Friday & 22.2 & 35 & 22.6 & 35 \\
Saturday & 21.2 & 34 & & 31 \\
\hline
\end{tabular}


Table 3 The TWI, total drinking fluids and water from food among participants consuming different levels of total drinking fluids

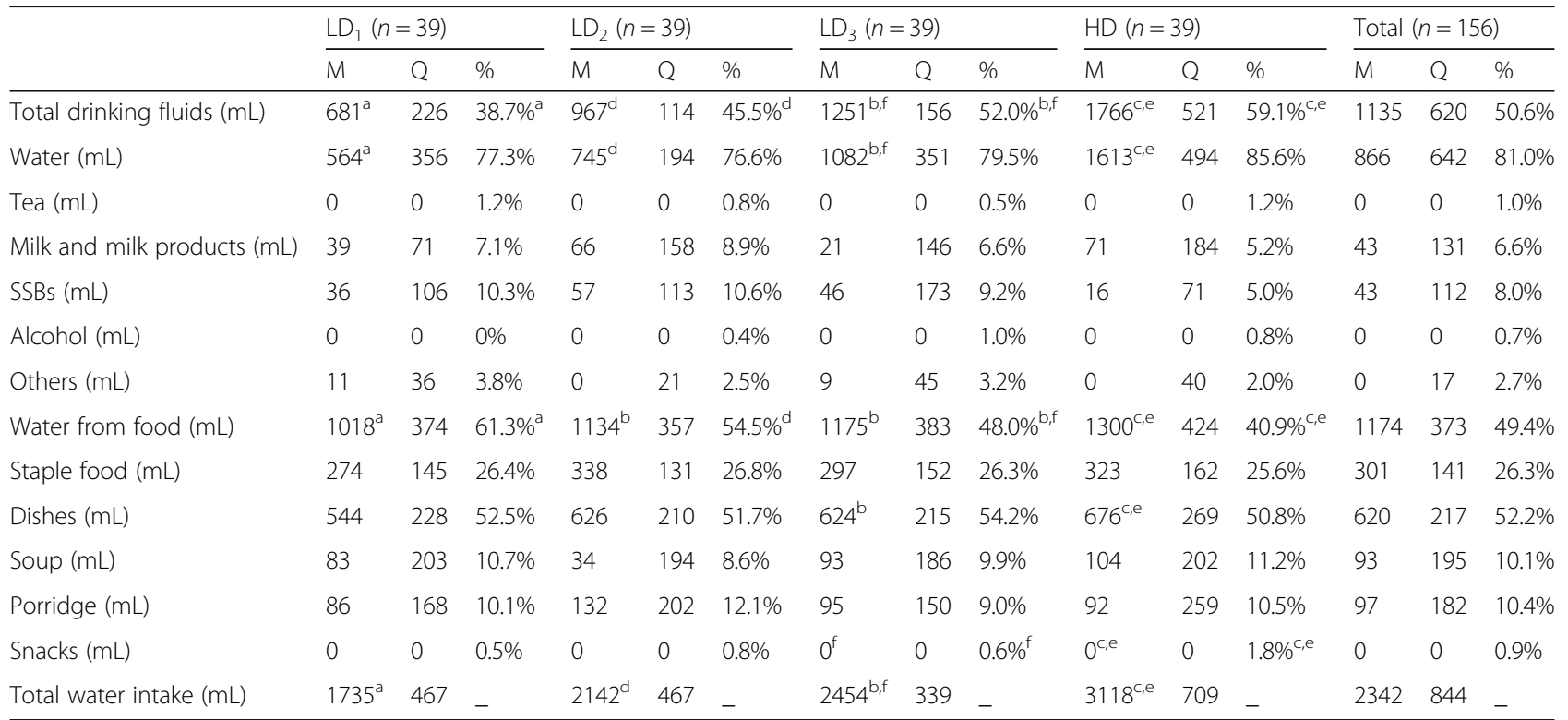

Values are shown as the median $(\mathrm{M})$ and quartile ranges $(\mathrm{Q})$

${ }^{a}$ There was statistically significant difference between $\mathrm{LD}_{1}$ and $\mathrm{LD}_{2}$ groups, $p<0.05$; ${ }^{\mathrm{b}}$ There was statistically significant difference between $\mathrm{LD}_{1}$ and $\mathrm{LD}_{3}$ groups, $p<0.05$; ${ }^{C}$ There was statistically significant difference between $\mathrm{LD}_{1}$ and HD groups, $p<0.05$; ${ }^{\mathrm{d}}$ There was statistically significant difference between $\mathrm{LD}_{2}$ and $\mathrm{LD}_{3}$ groups, $p<0.05$; ${ }^{\text {T}}$ There was statistically significant difference between $\mathrm{LD}_{2}$ and $\mathrm{HD}$ groups, $p<0.05$; ${ }^{\mathrm{f}}$ There was statistically significant difference between $\mathrm{LD}_{3}$ and HD groups, $p<0.05$

\%: Contributions of total drinking fluids and water from food to TWl; percentages of different fluids in total drinking fluids; proportions of water from different foods in water from food

There were statistical significances in the amounts of TWl, total drinking fluids and water from food $\left(X^{2}=121.262, P<0.001 ; X^{2}=145.319, P<0.001 ; X^{2}=18.941, P<\right.$ $0.001)$ among the four groups, respectively. There were statistical significances in the contributions of total drinking fluids and water from food to TWI, respectively $(F=86.910, P=0.000 ; F=86.910, P=0.000)$. There were statistical significances in the consumption of water among the four groups $\left(X^{2}=108.966, P<\right.$ 0.001). The water from dishes and snacks were different in the four groups $\left(X^{2}=12.549, P=0.006 ; X^{2}=8.746, P=0.033\right)$, but no significant differences were found in the staple food, soup and porridge $\left(X^{2}=7.377, P=0.061 ; X^{2}=3.160, P=0.368 ; X^{2}=1.838, P=0.607\right)$. The contributions of snacks to water from food among the four groups were different $\left(X^{2}=8.331, P=0.040\right)$

\section{Measurement of plasma indexes}

Statistically significant differences were found in the concentration of $\mathrm{Mg}$ among the four groups $(p<0.05)$. No statistically significant differences were found in plasma osmolality, the concentrations of $\mathrm{Na}, \mathrm{K}, \mathrm{Cl}, \mathrm{Ca}$ and phosphate among participants in the four groups $(p>0.05)$, as shown in Table 5.

\section{Discussion}

In this study, when the total drinking fluids increased significantly, the water from food and TWI increased significantly accordingly among the four groups; the proportions of total drinking fluids in TWI were increased. Whereas, the contributions of water from food to TWI were decreased simultaneously, which were higher than the results among participants both in low and high drinkers in France [22]. The findings indicated that, participants with higher total drinking fluids may tend to prefer taking in more water from food. It meant that participants with lower total drinking fluids would not compensate from food to increase the intake of TWI. Therefore, they may have more danger to be in dehydration status than others. In addition, study performed among Europeans showed that, adults with higher TWI was associated with higher nutritional quality of the diet, assessed by several dietary indices [47]. Besides, it was also showed that high water intake remained significantly associated with higher die quality among children aged 2 to 18 years [48].

Researches demonstrated that, TWI was strongly associated with 24-h urine volume, osmolality, USG and solute concentrations [21, 49]. Moreover, urine osmolality $\leq 800 \mathrm{mOsm} / \mathrm{kg}[13,46]$, was the indicator of optimal hydration status. In our study, when the total drinking fluids increased, the volume of 24-h urine increased, whereas, the 24-h osmolality, USG decreased among the four groups. Urine osmolality, USG and volume, but not plasma osmolality, responded to the changes in water intake [50]. Results of this study showed that, the 24-h urine osmolality of participants in $\mathrm{LD}_{1}, \mathrm{LD}_{2}$ and $\mathrm{LD}_{3}$ groups were higher than the standard, while the 24-h urine osmolality of participants in HD group was lower than the standard. Meanwhile, significantly more participants with the 24-h urine osmolality below the standard were in HD group than in other groups. Participants with lower total drinking fluids had less and more concentrated urine than participants with higher total drinking fluids, which indicated that participants with lower 
Table 4 The characteristics of $24 \mathrm{~h}$ urine among participants consuming different levels of total drinking fluids

\begin{tabular}{|c|c|c|c|c|c|c|c|c|c|c|}
\hline & \multicolumn{2}{|c|}{$\mathrm{LD}_{1}(n=39)$} & \multicolumn{2}{|c|}{$\mathrm{LD}_{2}(n=39)$} & \multicolumn{2}{|c|}{$\mathrm{LD}_{3}(n=39)$} & \multicolumn{2}{|c|}{$\mathrm{HD}(n=39)$} & \multicolumn{2}{|c|}{ Total $(n=156)$} \\
\hline & M & Q & M & Q & M & Q & M & Q & M & Q \\
\hline 24-h Volume (mL) & 1076 & 370 & $1256^{d}$ & 500 & $1462^{\mathrm{b}, \mathrm{f}}$ & 671 & $1869^{\mathrm{c}, \mathrm{e}}$ & 747 & 1370 & 668 \\
\hline 24-h urine Osmolality (mOsm/kg) & 730 & 238 & 671 & 337 & 512 & 303 & $430^{c, e}$ & 280 & 587 & 309 \\
\hline$(\leq 500 \mathrm{mOsm} / \mathrm{kg}, \mathrm{n}, \%)$ & \multicolumn{2}{|c|}{$5(12.8 \%)^{*}$} & \multicolumn{2}{|c|}{$13(33.3 \%)$} & \multicolumn{2}{|c|}{$18(46.2 \%)^{b}$} & \multicolumn{2}{|c|}{$22(56.4 \%)^{c}$} & \multicolumn{2}{|c|}{$58(37.2 \%)$} \\
\hline $\mathrm{Na}(\mathrm{mmol} / \mathrm{L})$ & 200 & 123 & 171 & 95 & 175 & 101 & $148^{c}$ & 110 & 175 & 101 \\
\hline $\mathrm{K}(\mathrm{mmol} / \mathrm{L})$ & 39.4 & 20 & 36.2 & 18.2 & $30.1^{b, f}$ & 19.7 & $26.7^{c, e}$ & 17.0 & 33.75 & 19.42 \\
\hline $\mathrm{Cl}(\mathrm{mmol} / \mathrm{L})$ & 202 & 106 & 174 & 101 & 168 & 114 & $148^{c}$ & 108 & 169 & 104 \\
\hline $\mathrm{Mg}(\mathrm{mmol} / \mathrm{L})$ & 2.90 & 0.96 & 3.11 & 1.39 & 2.42 & 1.26 & $1.89^{c, e}$ & 1.11 & 2.50 & 1.54 \\
\hline $\mathrm{Ca}(\mathrm{mmol} / \mathrm{L})$ & 2.47 & 2 & 2.21 & 1.59 & 2.10 & 1.25 & 1.55 & 1.06 & 2.09 & 1.54 \\
\hline Phosphate (mmol/L) & 15.91 & 6.54 & 17.36 & 12.66 & 13.34 & 10.56 & $11.45^{c, e}$ & 9.05 & 14.89 & 8.91 \\
\hline Creatinine $(\mathrm{mmol} / \mathrm{L})$ & 10.48 & 3.45 & $10.20^{d}$ & 6.82 & $8.24^{b}$ & 6.59 & $7.67^{c}$ & 4.97 & 8.95 & 5.17 \\
\hline Uric acid (mmol/L) & 2.76 & 0.92 & 2.79 & 1.22 & $2.07^{b}$ & 1.66 & $1.96^{\mathrm{cee}}$ & 1.14 & 2.39 & 1.33 \\
\hline Urea (mmol/L) & 230.30 & 108.13 & 231.50 & 162.87 & 179 & 135 & $154^{c, e}$ & 117 & 200.42 & 126.95 \\
\hline USG & 1.015 & 0.003 & 1.017 & 0.007 & 1.015 & 0.006 & $1.013^{c, e}$ & 0.002 & 1.015 & 0.005 \\
\hline $\mathrm{pH}$ & 6.8 & 0.5 & 6.7 & 0.3 & 6.7 & 0.3 & 6.7 & 0.3 & 6.7 & 0.3 \\
\hline
\end{tabular}

Values are shown as the median (M) and quartile ranges $(\mathrm{Q}){ }^{*}{ }^{*} X^{2}=23.215, P<0.05$;

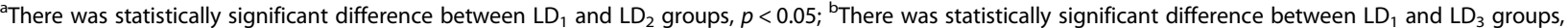
$p<0.05$; ${ }^{\circ}$ There was statistically significant difference between $\mathrm{LD}_{1}$ and $\mathrm{HD}$ groups, $p<0.05$; ${ }^{\mathrm{d}}$ There was statistically significant difference between $L D_{2}$ and $\mathrm{LD}_{3}$ groups, $p<0.05$; ${ }^{\mathrm{e}}$ There was statistically significant difference between $\mathrm{LD}_{2}$ and $\mathrm{HD}$ groups, $p<0.05$; ${ }^{\mathrm{f}}$ There was statistically significant difference between $\mathrm{LD}_{3}$ and HD groups, $p<0.05$

total drinking fluids maybe in dehydration, whereas, participants with high total drinking fluids maybe in optimal hydration status. Moreover, in France, the osmolality of urine among those with higher total drinking fluids and those with lower total drinking fluids were $371 \mathrm{mOsm} / \mathrm{kg}$ and $767 \mathrm{mOsm} / \mathrm{kg}$, respectively [21, 22]. Blood homeostasis is well regulated by physiological compensations from the kidneys, even after $24 \mathrm{~h}$ of water intake deprivation [51]. Indeed, plasma osmolality was maintained at a wide range of water intakes from the study of NHANES $ш$ [52]. Also, in our study, the plasma osmolality was 298-300 $\mathrm{mOsm} / \mathrm{kg}$ with a wide range of total drinking fluids from $681 \mathrm{~mL}$ to $1766 \mathrm{~mL}$, which indicated that plasma osmolality was not sensitive to the difference of total drinking fluids in free-living conditions, similarly to the study conducted before [14, 22, 53].

Regarding the drinking patterns, water was the main contributor of total drinking fluids among the four groups with the proportions higher than French, while the contributions of other beverages were lower than French [22]. The differences in culture and the accessibility of beverages could explain the observation. Regarding the types of beverages, SSBs have been shown to have detrimental effects on health $[30,54-56]$. In our study, SSBs were the second contributor of total drinking fluids among participants in $\mathrm{LD}_{1}, \mathrm{LD}_{2}$ and $\mathrm{LD}_{3}$ groups, which contributed to over $10 \%$ of total drinking fluids, while the milk and milk products were the second contributor among participants in HD group. This observation suggested that participants with higher total drinking fluids may have healthier drinking behaviors. However, the consumptions of milk and milk products of participants in the four groups, which ranged from $21 \mathrm{~mL}$ to $71 \mathrm{~mL}$, were much lower than the recommendation of China ( $300 \mathrm{~mL}$ ) [57]. In China, $300 \mathrm{~mL}$ of milk was the main source of calcium, which could supply about $39 \%$ of the reference of the intake of calcium [15]. Therefore, more interventions should be undertaken to increase the consumptions of milk and milk products. In addition, a study demonstrated that drinking pattern based on water and milk among children was associated with better hydration including lower urine osmolality, while drinking regular soda and other drinks but not water was associated with inferior hydration [58].

In this study, water from food was also an important source of TWI, accounting for $40.9-61.3 \%$ to TWI among the four groups. Regarding the sources of water from food, dishes (such as vegetables, meat) and staple food (including steamed bread and rice) were the first and second contributor among the four groups. Moreover, participants with higher total drinking fluids had more amounts of water from dishes (such as vegetables) and snacks (for instance, the fruits) than those with lower total drinking fluids. But there were no significant differences in the contributions of water from different sources of food.

Research showed that heights were also different among the people of China and other countries due to race differences, which contributes to difference in body surface area and has corresponding effects on water 


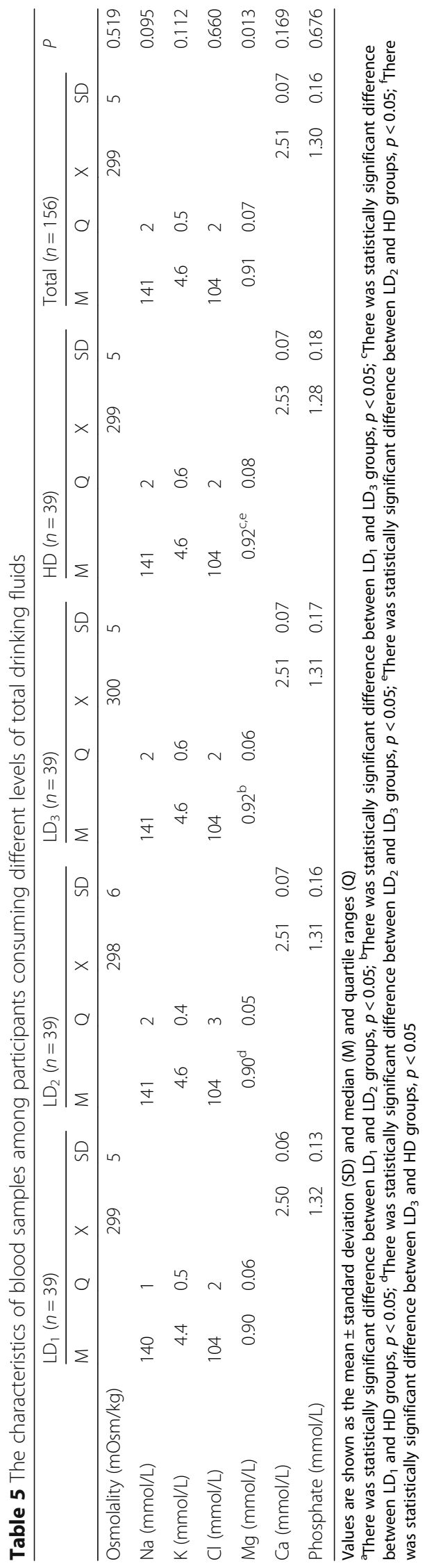


requirements [59]. In this research, significant differences were found in the height and weight when comparing groups $\mathrm{LD}_{2}, \mathrm{LD}_{3}$, HD groups with $\mathrm{LD}_{1}$ group, respectively, but with no differences between $\mathrm{LD}_{2}, \mathrm{LD}_{3}$ and HD groups. However, the indexes, such as the amounts of total drinking fluids and water from food, were different between $\mathrm{LD}_{2}, \mathrm{LD}_{3}$ and $\mathrm{HD}$ groups. In addition, there were also significant differences of hydration biomarkers, for instance, the volume of urine between $\mathrm{LD}_{2}, \mathrm{LD}_{3}$ and $\mathrm{HD}$ groups. It meant that, the differences of anthropometric measurements at baseline did not influence the results of drinking patterns and hydration biomarkers among participants from different groups.

In terms of the strengths, it was the first study investigated the drinking patterns and hydration biomarkers among participants with different total drinking fluids. Moreover, 7 -day $24 \mathrm{~h}$ fluid intake questionnaire was used to assess the total drinking fluids for seven consecutive days (two weekdays and one weekend day), which would reduce the recall bias. The duplicate portion method was used to assess the amounts of water from food, with all the foods were being weighed before and after participants ate for three consecutive days. In addition, $24 \mathrm{~h}$ urine was collected every time they urinated using specific container for three consecutive days (two weekdays and one weekend day), which would include incorporate factors fluctuating during weekdays and weekends. Moreover, the samples of urine collected by the participants, were stored at $+4{ }^{\circ} \mathrm{C}$ and sent to the laboratory for test immediately. All the tests were performed by professional investigators. Despite strengths mentioned above, the study employed did have limitations. This survey was performed with young adults only so extrapolation of the study findings to different age groups should be done with care. However, despite the limitation, the association between hydration status, drinking pattern and total drinking fluids intake remains meaningful. Future studies will determine the general application of our results to a wider population, including middle-aged adults and the elderly.

\section{Conclusions}

Participants with higher total drinking fluids had higher water from food and TWI than those with lower total drinking fluids. Participants with higher total drinking fluids had better hydration status and drinking pattern than those with lower total drinking fluids. Interventions should be undertaken to encourage people to drink an adequate amount of total drinking fluids, preferably water, in order to be in optimal hydration.

\section{Abbreviations}

LD: Low drinker; HD: High drinker; TWI: Total water intake; EFSA: European Food Safety Authority

\section{Acknowledgements}

We would like to thank investigators from Hebei University Health Science Center for participating in this project.

\section{Authors' contributions}

JZ participated in the data collection of the study, the drafting of the paper, and contributed to the analysis of the data. GM was responsible for designing, monitoring the implementation of the study and the finalization of manuscript. NZ and SD designed the study and were responsible for the quality management, the control of the implementation of the study and the analysis of the data. JZ and SL was responsible for the recruitment of participants. HH, YX, HC, SL and YW were responsible for the implementation of the study. All authors read and approved the final manuscript.

\section{Funding}

This work was supported by National Natural Science Foundation of China (81673146). The National Natural Science Foundation of China did not play a role in the design of the study, the collection, analysis and interpretation of the data and in writing the manuscript.

\section{Availability of data and materials}

The datasets generated and/or analyzed during the current study are available from the corresponding author on reasonable request.

\section{Ethics approval and consent to participate}

The study protocol was approved by the Peking University Institutional Review Committee. The ethical approval project identification code is IRB00001052-16071. This study was conducted according to the guidelines of the Declaration of Helsinki. All participants signed informed consent form before participating in the study.

\section{Consent for publication}

Not applicable.

\section{Competing interests}

The authors declare that they have no competing interests.

\section{Author details}

${ }^{1}$ Department of Nutrition and Food Hygiene, School of Public Health, Peking University, 38 Xue Yuan Road, Haidian District, Beijing 100191, China.

${ }^{2}$ Laboratory of Toxicological Research and Risk Assessment for Food Safety, Peking University, 38 Xue Yuan Road, Haidian District, Beijing 100191, China. ${ }^{3}$ Affiliated Hospital of Hebei University, 212 Yuhua Road, Lianchi District, Baoding 071000, China. ${ }^{4}$ School of Public Health, Hebei University Health Science Center, 342 Yuhua Road, Lianchi District, Baoding 071000, China. ${ }^{5}$ Chinese Nutrition Society, Room 1405, Beijing Broadcasting Building, No. 14 Jianguomenwai Street, Chaoyang District, Beijing 100191, China.

Received: 24 September 2019 Accepted: 19 March 2020

Published online: 08 April 2020

\section{References}

1. Popkin BM, D'Anci KE, Rosenberg H. Water, hydration, and health. Nutr Rev. 2010;68(8):439-58.

2. Jequier $\mathrm{E}$, Constant $\mathrm{F}$. Water as an essential nutrient: the physiological basis of hydration. Eur J Clin Nutr. 2010;64(2):115-23.

3. Munoz CX, Johnson EC, McKenzie AL, et al. Habitual total water intake and dimensions of mood in healthy young women. Appetite. 2015;92:81-6.

4. Savoie FA, Kenefick RW, Ely BR, et al. Effect of Hypohydration on muscle endurance, strength, anaerobic power and capacity and vertical jumping ability: a meta-analysis. Sports Med. 2015;45(8):1207-27.

5. Lewis JJ, Mark PF, Ruth MJ, et al. Does hypohydration really impair endurance performance? Methodological considerations for interpreting hydration research. Sports Med. 2019;49(suppl2):s103-14.

6. Suhr JA, Hall J, Patterson SM, Niinisto RT. The relation of hydration status to cognitive performance in healthy older adults. Int J Psychophysiol. 2004; 53(2):121-5.

7. Zhang N, Du SM, Zhang J, et al. Effects of dehydration and rehydration on the cognitive performances and mood among male college students in Cangzhou, China: a self-controlled trial. Int J Environ Res Public Health. 2019: 16:1891. 
8. D'Anci KE, Mahoney CR, Vibhakar A, Kanter JH, Taylor HA. Voluntary dehydration and cognitive performance in trained college athletes. Percept Mot Skills. 2009;109(1):251-69.

9. Ganio MS, Armstrong LE, Casa DJ, et al. Mild dehydration impairs cognitive performance and mood of men. Brit J Nutr. 2011;106(10):1535-43.

10. Stachenfeld NS, Leone CA, Mitchell ES, Freese E, Harkness L. Water intake reverses dehydration associated impaired executive function in healthy young women. Physiol Behav. 2018;185:103-11.

11. Wittbrodt MT, Melinda MS. Dehydration impairs cognitive performance. Med Sci Sports Exer. 2018:50:2360-8.

12. Joseph CW, William BF. Hydration status and cardiovascular function. Nutrients. 2019;11:1866.

13. Authority EFS. Scientific opinion on dietary reference values for water. EFSA J. 2010;8(3):1462.

14. Institute of Medicine. Dietary reference intakes for water, potassium, sodium, chloride, and sulfate. Washington DC: National Academy Press; 2005.

15. Chinese Nutrition Society. Chinese dietary nutrients reference intakes (2013). Beijing: Science Press; 2014.

16. Ferreira-Pêgo C, Guelinckx I, Moreno LA, et al. Total fluid intake and its determinants: cross-sectional surveys among adults in 13 countries worldwide. Eur J Nutr. 2015;54(S2):35-43.

17. Suh $\mathrm{HG}$, Kavouras SA. Water intake and hydration state in children. Eur J Nutr. 2019;58(2):475-96.

18. Ma G, Zhang Q, Liu A, et al. Fluid intake of adults in four Chinese cities. Nutr Rev. 2012;70(Suppl 2):S105-10.

19. Brooks CJ, Gortmaker SL, Long MW, Cradock AL, Kenney EL. Racial/ethnic and socioeconomic disparities in hydration status among US adults and the role of tap water and other beverage intake. Am J Public Health. 2017; 107(9):1387-94.

20. Hilary JB, Larry KW, David MA, et al. Cognitive performance in relation to hydration status and water intake among older adults, NHANES 2011-2014. Eur J Nutr. 2019. https://doi.org/10.1007/s00394-019-02152-9.

21. Zhang N, Du S, Tang Z, et al. Hydration, fluid intake, and related urine biomarkers among male college students in Cangzhou, China: a cross-sectional study - applications for assessing fluid intake and adequate water intake. Int J Environ Res Public Health. 2017;14(5): 513.

22. Perrier $\mathrm{E}$, Vergne $\mathrm{S}$, Klein $\mathrm{A}$, et al. Hydration biomarkers in free-living adults with different levels of habitual fluid consumption. Br J Nutr. 2013;109(9): 1678-87.

23. Lee KW, Shin D. A healthy beverage consumption pattern is inversely associated with the risk of obesity and metabolic abnormalities in Korean adults. J Med Food. 2018;00(0):1-11.

24. Brunkwall L, Almgren P, Hellstrand S, Orho-Melander M, Ericson U. Commonly consumed beverages associate with different lifestyle and dietary intakes. Int J Food Sci Nutr. 2018;70:1-10.

25. Daniels MC, Popkin BM. Impact of water intake on energy intake and weight status: a systematic review. Nutr Rev. 2010;68(9):505-21.

26. Duffey K, Poti J. Modeling the effect of replacing sugar-sweetened beverage consumption with water on energy intake, $\mathrm{HBI}$ score, and obesity prevalence. Nutrients. 2016;8(7):395.

27. Chang T, Ravi N, Plegue MA, Sonneville KR, Davis MM. Inadequate hydration, BMI, and obesity among US adults: NHANES 2009-2012. Ann Fam Med. 2016;14(4):320-4.

28. Madjd A, Taylor MA, Delavari A, et al. Effects of replacing diet beverages with water on weight loss and weight maintenance: 18-month follow-up, randomized clinical trial. Int J Obes. 2018:42:835-40.

29. Hu FB. Resolved: there is sufficient scientific evidence that decreasing sugar-sweetened beverage consumption will reduce the prevalence of obesity and obesity-related diseases. Obes Rev. 2013; 14(8):606-19.

30. Gui Z, Zhu Y, Cai L, et al. Sugar-sweetened beverage consumption and risks of obesity and hypertension in Chinese children and adolescents: a National Cross-Sectional Analysis. Nutrients. 2017;9(12):1302

31. Hodge AM, Bassett JK, Milne RL, English DR, Giles GG. Consumption of sugar-sweetened and artificially sweetened soft drinks and risk of obesity-related cancers. Public Health Nutr. 2018; 21(9):1618-26.

32. Ambrosini GL, Oddy WH, Huang RC, et al. Prospective associations between sugar-sweetened beverage intakes and cardiometabolic risk factors in adolescents. Am J Clin Nutr. 2013;98(2):327-34.
33. Parvin M, Emad Y, Golaleh A, et al. Consumption of sugar sweetened beverage is associated with incidence of metabolic syndrome in Tehranian children and adolescents. Nutr Metab. 2015;12(1):25.

34. Malik VS, Popkin BM, Bray GA, et al. Sugar-sweetened beverages, obesity, type 2 diabetes mellitus, and cardiovascular disease risk. Circulation. 2010; 121(11):1356-1364.35.

35. Sampasa-Kanyinga $H$, Hamilton HA, Chaput JP. Sleep duration and consumption of sugar-sweetened beverages and energy drinks among adolescents. Nutrition. 2018;48:77-81.

36. Grigg D. The worlds of tea and coffee: patterns of consumption. Geo J. 2002;57:283-94.

37. Kant AK, Graubard BI, Atchison EA. Intakes of plain water, moisture in foods and beverages, and total water in the adult US population--nutritional, meal pattern, and body weight correlates: National Health and nutrition examination surveys 1999-2006. Am J Clin Nutr. 2009;90(3):655-63.

38. Manz F, Johner SA, Wentz A, Boeing H, Remer T. Water balance throughout the adult life span in a German population. Br J Nutr. 2012; 107(11):1673-81.

39. Tani $Y$, Asakura $K$, Sasaki $S$, et al. The influence of season and air temperature on water intake by food groups in a sample of free-living Japanese adults. Eur J Clin Nutr. 2015:69(8):907-13.

40. Hu X, Zhang Q, Zhang W, et al. Water intake sources analysis of adults in four cities of China in summer. Chin J Prev Med. 2011:45(8):688-91 (In Chinese).

41. Zhang N, Du S, Tang Z, Zheng M, Ma G. Effect of water supplementation on cognitive performances and mood among male college students in Cangzhou, China: study protocol of a randomized controlled trial. Int J Environ Res Public Health. 2017;14(9):966.

42. General Administration of Quality Supervision, Inspection and Quarantine of China. General Standard for Beverages GB/T 1-789-2015. Beijing: Standardization Administration of China; 2015

43. Zhang J, Zhang N, Liang S, et al. The amounts and contributions of total drinking fluids and water from food to total water intake of young adults in Baoding, China. Eur J Nutr. 2018;58:2669-77.

44. Standardization Administration of China. National Food Safety Standard GB 5009.3-2016. In: Determination of Moisture in Foods. Beijing: China Standard Press; 2016.

45. Institute for Nutrition and Health, Chinese Center for Disease Control and Prevention. China Food Composition. Beijing: Peking University Medicine Press; 2009.

46. Perrier ET, Buendia-Jimenez I, Vecchio $M$, et al. Twenty-four-hour urine osmolality as a physiological index of adequate water intake. Dis Markers. 2015:2015:231063.

47. Gazan R, Sondey J, Maillot M, Guelinckx I, Lluch A. Drinking water intake is associated with higher diet quality among French adults. Nutrients. 2016; 8(11):689.

48. Leung CW, Dimatteo SG, Gosliner WA, et al. Sugar-sweetened beverage and water intake in relation to diet quality in U.S. children. Am J Prev Med. 2018 54(3):394-402.

49. Perrier $E$, Rondeau $P$, Poupin $M$, et al. Relation between urinary hydration biomarkers and total fluid intake in healthy adults. Eur J Clin Nutr. 2013; 67(9):939-43.

50. Perrier E, Demazieres A, Girard N, et al. Circadian variation and responsiveness of hydration biomarkers to changes in daily water intake. Eur J Appl Physiol. 2013;113(8):2143-51.

51. Pross N, Demazieres A, Girard N, et al. Influence of progressive fluid restriction on mood and physiological markers of dehydration in women. $\mathrm{Br}$ J Nutr. 2013;109(2):313-21.

52. Campbell SM. Hydration needs throughout the lifespan. J Am Coll Nutr. 2007;26(5 Suppl):585S-7S.

53. Johnson EC, Munoz CX, Jimenez $\mathrm{L}$, et al. Hormonal and thirst modulated maintenance of fluid balance in young women with different levels of habitual fluid consumption. Nutrients. 2016;8(5):302.

54. Richelsen B. Sugar-sweetened beverages and cardio-metabolic disease risks. Curr Opin Clin Nutr Metab Care. 2013;16(4):478-84.

55. Malik VS, Pan A, Willett WC, Hu FB. Sugar-sweetened beverages and weight gain in children and adults: a systematic review and meta-analysis. Am J Clin Nutr. 2013:98(4):1084-102

56. Qin Z, Xu F, Ye Q, et al. Sugar-sweetened beverages and school students' hypertension in urban areas of Nanjing, China. J Hum Hypertens. 2018;32: 392-6. 
57. Chinese Nutrition Society. Chinese Dietary Guidelines (2016). Beijing: People's Medical Publishing House; 2016.

58. Bougatsas D, Arnaoutis $\mathrm{G}$, Panagiotakos DB, et al. Fluid consumption pattern and hydration among 8-14 years-old children. Eur J Clin Nutr. 2018; 72(3):420.

59. Zhang YY, Liu PY, Lu Y, et al. Race and sex differences and contribution of height: A study on bone size in healthy Caucasians and Chinese. Am J Hum Biol. 2005;17:568-75.

\section{Publisher's Note}

Springer Nature remains neutral with regard to jurisdictional claims in published maps and institutional affiliations.

- fast, convenient online submission

- thorough peer review by experienced researchers in your field

- rapid publication on acceptance

- support for research data, including large and complex data types

- gold Open Access which fosters wider collaboration and increased citations

- maximum visibility for your research: over $100 \mathrm{M}$ website views per year

At $\mathrm{BMC}$, research is always in progress. 